\title{
Infant with diabetes - a diagnostic challenge for paediatricians
}

\author{
Agnieszka Brandt-Varma, Małgorzata Myśliwiec \\ Department of Paediatrics, Diabetology and Endocrinology, Medical University of Gdansk, Poland
}

\begin{abstract}
Common symptoms of diabetes in newborns and infants are uncharacteristic, what often leads to the delay in diagnosis and implementation of proper treatment. Diabetes is rare disease in this life period, but paediatricians should remember about checking glucose level in unwell babies. Children with neonatal diabetes are characterised by low birth weight, significant hyperglycaemia, often with concomitant metabolic acidosis. Hyperglycaemia diagnosed in the neonatal period requires the immediate implementation of insulin therapy, which is essential for proper development and growth of the child.

This paper describes a 30-day old boy with permanent neonatal diabetes and all diagnostic and therapeutic difficulties before the final diagnosis was made.
\end{abstract}

\section{KEY WORDS:}

infant, hyperglycaemia, neonatal diabetes.

\section{INTRODUCTION}

The most common form of diabetes in children and adolescents is autoimmune type 1 diabetes. Diabetes in children usually is diagnosed based on symptoms as polyuria, polidypsia, weight loss and hyperglycaemia, but sometimes less typical clinical picture may lead to delay in proper diagnosis [1]. The etiology of diabetes in the neonatal period is still a subject of many studies. Neonatal diabetes is a rare metabolic disorder with prevalence of about $1: 200000$ infants [2,3] and it is defined as diabetes diagnosed before $9^{\text {th }}$ month of life [1]. It may be transient (transient neonatal diabetes mellitus - TNDM) and persistent (permanent neonatal diabetes mellitus - PNDM). Approximately $50 \%$ of cases of persistent neonatal diabetes is caused by activating mutations in the gene KCJN11 $[2,3]$. Development of mutations in the gene KCJN11 encoding a subunit of ATP-sensitive potassium channel Kir 6.2 was an extremely important discovery in the field of diabetes. The mechanism of this disease lies in sustained activation and opening of potassium channels in pancreatic beta cells, leading to the cell membrane hyperpolarisation and calcium channels closure, which disables the insulin secretion $[5,6]$. Potassium channel is essential part of glucose stimulated insulin secretion in pancreatic $\beta$ cells [6]. PNDM usually manifests in the first 6 months of life $[2,3,7]$. Children with neonatal diabetes usually present with low birth weight, significant hyperglycemia, with concomitant metabolic acidosis. Patients with mutations in KCNJ11 gene due to the presence of $\mathrm{K}_{\text {ATP }}$ channels in the brain may present attention deficit hyperactivity disorder, sleep disruptions, developmental delays and seizures. They can present mild delays without seizures or more severe delays with seizures (DEND syndrome) [8]. In this group of patients antibodies specific for beta-cell destruction (GAD Ab - anti-glutamic acid decarboxylase antibodies, IAA - anti-insulin antibodies, ICA - anti-islets antibodies) are absent $[3,9,10]$. Hyperglycaemia in the neonatal period requires the immediate implementation of insulin therapy. Treatment of diabetes in this age group is very difficult, due to the need for precise dosing of insulin. It is known that diabetes caused by mutations in the gene KCJN11 is sensitive to sulfonylurea treatment $[4,11]$.

\section{ADDRESS FOR CORRESPONDENCE:}

Agnieszka Brandt-Varma, Department of Paediatrics, Diabetology and Endocrinology, Medical University of Gdansk, 7 Dębinki St., 80-952, Gdansk, Poland, ORCID: 0000-0002-0125-8199, e-mail: agnabrandt@gmail.com 


\section{CASE REPORT}

The report presents a male patient admitted to the Paediatric Diabetes Department in Medical University of Gdansk, Poland on $30^{\text {th }}$ day of his life with suspicion of diabetes. Pregnancy period was uneventfull, child was delivered by caesarean section, with a birth weight of 2280 grams and Apgar score of 10 points. Father of the child was healthy, mother was under the care of a neurologist due to myasthenia gravis. There was no family history of type 1 diabetes, while type 2 diabetes was diagnosed in great-grandmother of the child.

The child was fed with formula milk from the first day of life. In the first two weeks of life newborn was thriving. During third week of life problems with feeding had started with poor appetite and vomiting. In $25^{\text {th }}$ day of life baby's body weight was 3000 grams, and from that day a gradual loss of body weight was observed. Clinical suspicion of urinary tract infection was excluded on the basis of microbiological urine test. Due to diagnosed anemia, the treatment with iron supplements was introduced. From $28^{\text {th }}$ day of life baby's baby was less active and had difficulties in swallowing milk. On $29^{\text {th }}$ day of life the patient was admitted to Paediatric Surgical Department, due to pylorostenosis suspicion based on the abdominal clinical symptoms. Due to the severe condition of the baby with clinical signs of dehydration and reported increased urination by mother, blood glucose and acid-base balance were performed. Based on tests the suspicion of diabetes was

TABLE 1. Biochemical parameters on admission and after 12, 24 and 60 hours of intravenous treatment

\begin{tabular}{|c|c|c|c|c|}
\hline Parameter & On admission & $12 \mathrm{~h}$ & $24 \mathrm{~h}$ & $60 \mathrm{~h}$ \\
\hline $\mathrm{Hgb}(\mathrm{g} / \mathrm{dl})$ & 8.7 & 11.4 & - & 11.8 \\
\hline $\mathrm{RBC}(\mathrm{T} / \mathrm{l})$ & 3 & 3.8 & - & 4 \\
\hline WBC (G/I) & 23.42 & 9.98 & - & 7.78 \\
\hline $\mathrm{PLT}(\mathrm{G} / \mathrm{I})$ & 447 & 275 & - & 193 \\
\hline CRP (mg/l) & 7.1 & 7.7 & - & 1.4 \\
\hline $\mathrm{pH}$ & 7.01 & 7.27 & 7.36 & 7.38 \\
\hline $\mathrm{HCO}_{3}(\mathrm{mmol} / \mathrm{l})$ & 3 & 7.2 & 16.8 & 21.1 \\
\hline $\mathrm{BE}(\mathrm{mmol} / \mathrm{l})$ & -25 & -16.7 & -7 & -1.8 \\
\hline Creatinin (mg/dl) & 1.38 & 1.09 & 0.61 & 0.48 \\
\hline AST (U/I) & 15 & - & - & 16 \\
\hline ALT (U/I) & 16 & - & - & 38 \\
\hline $\begin{array}{l}\text { Serum osmolarity } \\
\left(\mathrm{m} 0 \mathrm{sm} / \mathrm{kg} \mathrm{H}_{2} \mathrm{O}\right)\end{array}$ & 399 & 346 & 324 & 300 \\
\hline INR & 1.11 & - & - & - \\
\hline Glucose (mmol/l) & 44.4 & 18.1 & 10.4 & 8.5 \\
\hline $\mathrm{Na}(\mathrm{mEq} / \mathrm{l})$ & 157 & 154 & 149 & 143 \\
\hline $\mathrm{K}(\mathrm{mEq} / \mathrm{l})$ & 6.3 & 5.6 & 4.7 & 4.9 \\
\hline
\end{tabular}

Hgb - hemoglobin, RBC - red blood cells, WBC - white blood cells, PLT - platelets, CRP - C-reactive protein, $\mathrm{pH}$ - base and acid balance, $\mathrm{HCO}$ - sodium bicarbonate, $B E$ - base excess, AST - aspartate transaminase, ALT - alanine transaminase, INR - international normalized ratio, $\mathrm{Na}$ - sodium, $K$ - potassium made (blood glucose $39 \mathrm{mmol} / \mathrm{l}, \mathrm{pH} 7.0$ ), and child was urgently transferred by ambulance to the Department of Pediatric Diabetology. On admission to Diabetology Department the infant was in a poor general condition, his heart rate was 185 per minute, respiratory rate 80 per minute, skin pallor, cool, dry mucosa, sunken fontanel, the baby was not active with crying response to painful stimuli, body weight on admission was 2750 grams. In laboratory tests hyperglycaemia (44.4 $\mathrm{mmol} / \mathrm{l})$, hyperosmolarity (399 $\left.\mathrm{mOsm} / \mathrm{kg} \mathrm{H}_{2} \mathrm{O}\right)$, hypernatraemia (157 mEq/l), severe metabolic acidosis ( $\mathrm{pH} 7.0$ ), anemia, leukocytosis, markedly elevated serum creatinine $(1.38 \mathrm{mg} / \mathrm{dl})$ and slightly elevated parameters of inflammation (CRP $7.1 \mathrm{mg} / \mathrm{l}$ ) were noticed (Table 1). Intravenous fluids, insulin and antibiotic were prescribed. The baby received initially bolus of $10 \mathrm{ml} / \mathrm{kg}$ of $0.9 \% \mathrm{NaCl}$ and then fluids based on calculations of maintenace and deficit of water. The patient received intravenous insulin initially in dose of $0.05 \mathrm{unit} / \mathrm{kg} / \mathrm{hour}$, and then gradually the dose of insulin was increased to $0.1 \mathrm{unit} / \mathrm{kg} /$ hour $[1,11]$. The empirical antibiotic therapy was started. Due to anemia and poor general condition ( $\mathrm{Hgb} 8.7 \mathrm{~g} / \mathrm{dl}$, RBC $3.0 \mathrm{~T} / \mathrm{l}$ ) the child required a transfusion of red blood cells. During the first 10 hours of intensive therapy, the condition of the baby remained very serious, but stable. Child presented with tachycardia and increased respiratory rate, and then gradually started to improve. Every 60 minutes glucose level was checked, every 2 hours biochemical tests and blood gases analysis were performed. The child had also ultrasound measurement of IVC/Ao ratio (inferior vena cava to aorta) performed, which is a useful parameter in the evaluation of the vascular fill [10]. An emergency abdominal, lung and brain ultrasonography, ophthalmic and neurological examination showed no significant abnormalities. In the third day of hospitalization and intensive intravenous treatment normal parameters of water-electrolyte and acid-base balance were achieved. After 72 hours of intravenous treatment the continues subcutaneous inulin infusion by personal insulin pump was implemented. Initially, the daily insulin dose was $1.2 \mathrm{unit} / \mathrm{kg} / \mathrm{day}$, on the $3^{\text {rd }}$ day of treatment it decreased to $1 \mathrm{unit} / \mathrm{kg} /$ day. The child was fed every 3 hours with the initial volume of $100-130 \mathrm{ml}$ of formula milk. Child started gaining weight properly, from 25 to 35 grams per day. In subsequent days doses of insulin given as basal and boluses were modified and satisfactory glycaemic profile was achieved. Parents were trained how to use personal insulin pump.

The follow-up laboratory tests showed normal levels of thyroid hormones, renal function parameters and liver function tests (Table 1). In immunological tests, there was no signs of autoimmune diabetes and autoimmune thyroiditis. Abdominal ultrasound examination, ECG and echocardiography were within the normal range. Due to suspicion of neonatal diabetes genetic test was performed and the $\mathrm{R} 201 \mathrm{H}$ mutation in the gene KCNJ11 was found, which allowed to withdrawn insulin and implement sulfonylourea 
treatment at the age of 5 months. Patient was switched from insulin to glibenclamide in inpatient ward slowly with starting dose of $0.1 \mathrm{mg} / \mathrm{kg} /$ day to $0.5 \mathrm{mg} / \mathrm{kg} /$ day with good control of glucose profile in continues glucose monitoring.

\section{DISCUSSION}

Neonatal diabetes is most frequently caused by potassium channel dysfunction in pancreatic beta cells. Potassium channel, despite the continuous influx of glucose into beta cells remains permanently open, resulting in membrane hyperpolarization, closure of calcium channels and impaired insulin secretion $[4,5]$. A patient with PNDM is characterized by low birth weight, development of diabetes in the first months of life, with concomitant significant hyperglycemia and metabolic acidosis [3, 9]. All these characteristics of PNDM were found in the presented case. In neonates and infants there is a number of diseases with nonspecific symptoms that are more common than diabetes. Early diagnosis of diabetes and starting of appropriate treatment at the age of early infancy is often very difficult. In presented case other diseases like urinary tract infection, gastrointestinal defects and anemia were suspected and diabetes diagnosis was delayed and made after almost 2 weeks of symptoms presence. Urinary tract infection was excluded based on negative urine cultures result, but unfortunately common urine test was not performed and glycosuria was missed at that point. Early diagnosis is essential for implementation of appropriate treatment and prevention of severe metabolic acidosis and its harmful effects to young baby. In this case, difficulties with diagnosis, led to delay of treatment and deterioration of clinical condition of the baby. At the time of diagnosis it was already very difficult to treat such severe symptoms of disturbances in fluid and electrolyte and acid-base balance [12]. The patient required 72 hours of intravenous therapy and blood product transfusion.

In the described case the cause of neonatal diabetes was a $\mathrm{R} 201 \mathrm{H}$ mutation in the gene KCNJ11, which enabled the subsequent treatment with sulfonylurea and insulin withdrawal. Sulfonylureas, widely used in type 2 diabetes, close KATP channel, which stimulate insulin secretion [4, 9]. Molecular diagnostic methods allow to confirm the mutations and to start appropriate treatment of neonatal diabetes.

\section{CONCLUSIONS}

Diagnosis of diabetes without delays allows for proper treatment and prevents severe life-threatening complications due to late diagnosis. Early diagnosis of diabetes manifesting up to 6 months of age is difficult, but always should be taken under consideration. As the blood glucose measurement is very simple and cost-effective test, clinicians should be encouraged to perform it in every unhealthy newborn and infant.

\section{DISCLOSURE}

The authors declare no conflict of interest.

\section{REFERENCES}

1. Zalecenia kliniczne dotyczące postępowania u chorych na cukrzycę 2020. Stanowisko Polskiego Twarzystwa Diabetologicznego. Diabetologia Praktyczna 2020; 6: 1.

2. Tamaro P, Flanagan E, Zadek B, et al. Kir 6.2 mutation causing severe functional effects in vitro produces neonatal diabetes without the expected neurological complications. Diabetologia 2008; 51: 801-810.

3. Lemelman MB, Letourneau L, Greeley SAW. Neonatal diabetes mellitus: an update on diagnosis and management. Clin Perinatol 2018; 45: 41-59.

4. Rubio-Cabezas O, Klupa T, Malecki MT; CEED3 Consortium. Permanent neonatal diabetes mellitus - the importance of diabetes differential diagnosis in neonates and infants. Eur J Clin Invest 2011; 41: 323-333.

5. Antosik K, Borowiec M. Genetic factors of diabetes. Arch Immunol Ther Exp (Warsz) 2016; 64 (Suppl 1): 157-160.

6. Sagen JV, Raeder H, Hathout E, et al. Permanent neonatal diabetes due to mutation in KCNJ 11 encoding Kir 6.2: patent characteristics and response to sulfonylurea therapy. Diabetes 2004; 53: 2713-2718.

7. Gloyn AL, Pearson ER, Antcliff JF. Activing mutation in the gene encoding the ATP-sensitive potassium-chanel subunit Kir 6.2 and permanent neonatal diabetes. N Engl J Med 2004; 350: 1838-1849.

8. Carmody D, Pastore AN, Landmeier KA, et al. Patients with KCNJ11-related diabetes frequently have neuropsychological impairments compared with sibling controls. Diabet Med 2016; 33 : 1380-1386.

9. Noczyńska A, Zubkiewicz-Kucharska A, Salamonowicz B. Threeyear observation of permanent neonatal diabetes. Pediatr Endocrinol Diabetes Metab 2010; 16: 50-54.

10. Pearson ER, Flechtner I, Njølstad PR, et al. Switching from insulin to oral sulfonylureas in patients with diabetes due to Kir6.2 mutations. N Engl J Med 2006; 355: 467-477.

11. Ashcroft FM. The Walter B. Cannon Physiology in Perspective Lecture. ATP-sensitive $\mathrm{K}+$ channels and disease: from molecule to malady. Am J Physiol Endocrinol Metab 2007; 293: E880-E889.

12. Kosiak W, Swieton D, Piskunowicz M. Sonographic inferior vena cava/aorta diameter index, a new approach to the body fluid status assessment in children and young adults in emergency ultrasound preliminary study. Am J Emerg Med 2008; 26: 320-325.

13. ISPAD’s Clinical Practice Consensus Guidelines 2018. 